Research Article

\title{
Dust Particle Size Distributions during Spring in Yinchuan, China
}

\author{
Jiangfeng Shao and Jiandong Mao \\ School of Electrical and Information Engineering, Beifang University of Nationalities, Yinchuan 750021, China \\ Correspondence should be addressed to Jiandong Mao; mao-jiandong@163.com
}

Received 14 May 2015; Revised 30 August 2015; Accepted 7 September 2015

Academic Editor: Enrico Ferrero

Copyright (C) 2016 J. Shao and J. Mao. This is an open access article distributed under the Creative Commons Attribution License, which permits unrestricted use, distribution, and reproduction in any medium, provided the original work is properly cited.

\begin{abstract}
Dust particle size distributions in Yinchuan, China, were measured during March and April 2014, using APS-3321 sampler. The distributions were measured under different dust conditions (background, floating dust, blowing dust, and dust storm) and statistical analyses were performed. The results showed that, under different dust conditions, the instantaneous number concentrations of dust particles differed widely. For example, during blowing sand and dust storm conditions, instantaneous dust particles concentrations varied substantially, while, under floating dust conditions, concentration differences were relatively small. The average dust particles size distributions were unimodal under all dust conditions, but the average surface area and mass size distributions were all bimodal. These distributions had peaks in different locations under different dust conditions. Under different dust conditions, wind speed and humidity were very important factors for particles size distributions. With increasing wind speed and decreasing humidity, fine particles were dominant in the atmosphere and the number and mass distributions of the coarse particles were indicative of long-range transport from surrounding deserts. Different dust conditions had different influences on $\mathrm{PM}_{1}, \mathrm{PM}_{2.5}$, and $\mathrm{PM}_{10}$ concentrations.
\end{abstract}

\section{Introduction}

A variety of suspended solid and liquid particles exist in the atmosphere, including dust, smoke, microorganisms, pollen, cloud droplets, ice, and snow. The multiphase system that contains these suspended solid or liquid particles and their gas carrier is called an aerosol $[1,2]$. Aerosols have direct and indirect effects on the climate. The direct effects can lead to imbalances in the Earth's radiation through scattering and absorption of solar radiation. Indirect effects can also affect the radiation balance through changing cloud microphysical properties, which can influence cloud radiative properties $[3,4]$. Dust particles are the main components of troposphere aerosols and can have a significant impact on climate. During spring, dust events frequently occur in northern China and many dust particles enter the atmosphere. Through the atmospheric circulation, these particles can be transported into densely populated areas, which can have adverse effects on the environment and human health [5-10]. Among other negative effects, the micro- or nanoscale dust particles have a significant impact on the human respiratory system [1]. To study the impacts of dust particles on the atmosphere, detailed analyses on the physical characteristics of dust particles are required, including the number concentrations and particle size distributions.

Yinchuan, a city located in northwest China, is the capital of the Ningxia Hui Autonomous Region of China. It lies to the east of Helan Mountain, between the Tengger Desert and $\mathrm{Mu}$ Us Desert. The Badain Jaran Desert and Ulan Buh Desert are located to the northwest of the city, and the Yellow River passes through the city. Yinchuan experiences a typical temperate continental climate and during spring and winter dust episodes frequently occur. For example, during spring of 2013, large dust storm events occurred eight times. This was more during spring of 2012, when dust storm which occurred in 2013 was 16 days earlier than in 2012; the dust storm intensities in 2013 were greater than in 2012. These dust events have a significant impact on the lives and productivities of exposed populations. It is necessary to study dust particles properties in Yinchuan.

Since the 1970s, many researchers have studied dust particles from deserts or their downstream areas by using a variety of methods. In the Mojave Desert, Sverdrup et al. collected dust particles originating from the southern coast of the United States. These particles increased aerosol volume 
concentrations six times compared to a background day, which highlighted the transport of dust particles between different regions [11]. Through many measurements, Porter and Clarke found that dust particles originating from Asia that settled in Hawaii through long-range transport had different peaks in their size distributions, compared with those of longrange transported Saharan dust particles, highlighting that particles size distributions are influenced by transport time [12]. Haywood et al. measured the optical properties and direct radiative effects of two Saharan dust episodes using aircraft data and obtained dust particle size distributions at different heights [13]. Chun et al. used an optical particle measurement system to study dust particles size distributions under different meteorological conditions [14].

In China, a number of studies have focused on microphysical properties of dust particles. Quan et al. used an Anderson sampler to study differences in particle size distributions and concentrations between dust sources and downstream areas during a single dust event [15]. Niu and Sun used an APS-3310A instrument on an aircraft to study dust particles size distributions and their changes at different heights over several deserts in northwest China. The results showed that the dust particle number concentrations at high altitudes were closely related to the desert surface conditions, and number concentrations over deserts were higher than those over land used for growing vegetables [16]. Gu and Niu used an APS-3310A instrument to measure dust particle size distributions and number concentrations under different meteorological conditions in Bayinhaote and Yanchi from April to May 1998 and Yinchuan in April 1999 [9]. Additionally, in the Hunshandake Desert, Chen et al. obtained the dust particle size distributions using a PMS Fssp-100 laser particle spectrometer under different meteorological conditions [17].

Previous studies have focused on short-term episodes, limiting detailed evaluations of different dust conditions. A few studies have taken place in Yinchuan, despite widespread changes to the surrounding environment. This highlights the importance of systematically investigating the physical properties of dust particles in Yinchuan. In this study, measurements of the dust particle size distributions were performed using an APS-3321 (discussed in Section 2) under different meteorological conditions during March and April 2014. Under different dust conditions, the instantaneous concentration evolution, average size distribution, proportion of coarse and fine particles, and the impacts of different dust conditions on $\mathrm{PM}_{1}, \mathrm{PM}_{2.5}$, and $\mathrm{PM}_{10}$ were analyzed. This study provides important information for simulating the radiative effects of dust on the climate and the impact of dust particles on air quality.

\section{Materials and Methods}

The APS-3321 (TSI, USA) was used to measure aerodynamic particle size distributions and concentrations. It can measure the total concentrations of aerodynamic particle diameters that are larger than $0.37 \mu \mathrm{m}$ and it divides aerosol particles, which range from 0.5 to $20 \mu \mathrm{m}$ in aerodynamic diameter, into 52 different bins using a logarithmic scale. It can also measure particle number concentrations ranging from 0.001
TABle 1: Measurement results from March and April 2014 in Yinchuan area.

\begin{tabular}{lcc}
\hline Measurement time & $\begin{array}{c}\text { Number of } \\
\text { samples }\end{array}$ & $\begin{array}{c}\text { Meteorological } \\
\text { condition }\end{array}$ \\
\hline 2014.03.17 08:00-11:40 & 45 & Blowing sand \\
2014.03.17 12:05-2014.03.18 01:00 & 156 & Floating dust \\
2014.03.27 05:40-10:50 & 63 & Blowing sand \\
2014.03.27 11:25-13:45 & 29 & Floating dust \\
2014.04.01 12:15-21:40 & 114 & Background \\
2014.04.24 08:00-18:45 & 130 & Dust storm \\
2014.04.24 19:10-21:30 & 29 & Floating dust \\
\hline
\end{tabular}

to $10^{4} \mathrm{~cm}^{-3}$ and the mass concentration from $0.001 \mu \mathrm{g}$ to $10^{6} \mu \mathrm{g}$. The instrument uses dual laser beam aerodynamic particle size methods. During measurements, two orthogonally focused beams vertically pass through these particles and the instrument calculates the flight time of each particle. From this information the instrument calculates particle speeds, which are closely related to the aerodynamic diameter of aerosol particles. To quantify the relationship between flying velocity and particle size, the polystyrene rubber balls of known sizes are used to calibrate the instrument.

In this study, the APS-3321 and AIM (Aerosol Instrument Manager) software package were combined to measure the real-time dust particles concentration and size distribution during March and April 2014 in Yinchuan. Measurements were taken at the number 17 teaching building at a height of $20 \mathrm{~m}$ at the Beifang University of Nationalities $\left(106^{\circ} 29^{\prime} \mathrm{E}\right.$, $38^{\circ} 13^{\prime} \mathrm{N}$ ) in the Xixia District of Yinchuan. Because the campus was far away from the main industrial pollution sources, the measurements reflected the physical dust particle properties of the Yinchuan area. During each measurement the sampling interval was $5 \mathrm{~min}$ and the sampling process was uninterrupted.

\section{Results and Discussion}

3.1. Analysis of Instantaneous Concentration Evolutions of Dust Particles. Generally, dust conditions can be divided into three main types: floating dust, blowing sand, and dust storm [18]. Floating dust is a meteorological process in which dust particles are uniformly suspended in the atmosphere and the horizontal visibility is less than $10 \mathrm{~km}$. During blowing sand conditions the wind blows dust particles from the ground into the air, decreasing the horizontal visibility to between 1 and $10 \mathrm{~km}$. During dust storm events, the strong wind vigorously blows ground-based dust particles and makes the atmosphere very hazy producing horizontal visibilities less than $1 \mathrm{~km}$ or even less than $500 \mathrm{~m}$ [19]. Generally, particles during floating dust conditions are made up of a portion of undeposited particles produced during blowing sand and dust storm conditions. Measurement results from background days and floating dust, blowing sand, and dust storm conditions during the March and April 2014 are presented in Table 1.

Figure 1 shows the instantaneous particle numbers and mass concentrations of dust particles under three types of 


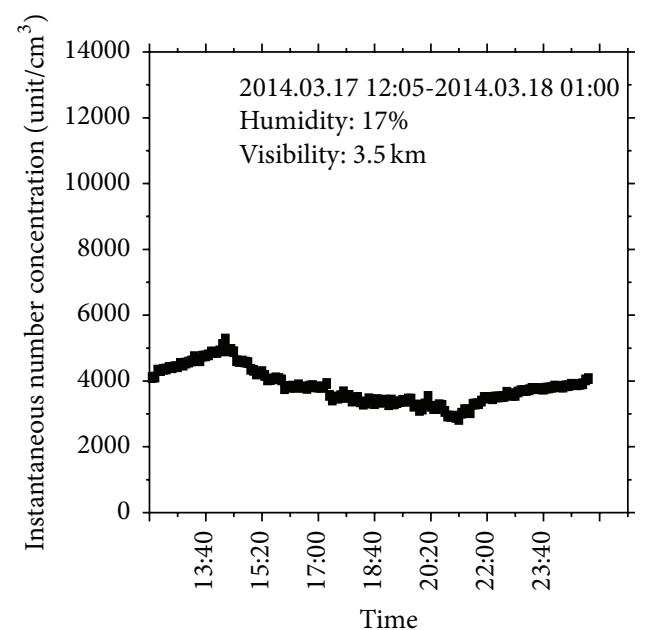

- Floating dust

(a)

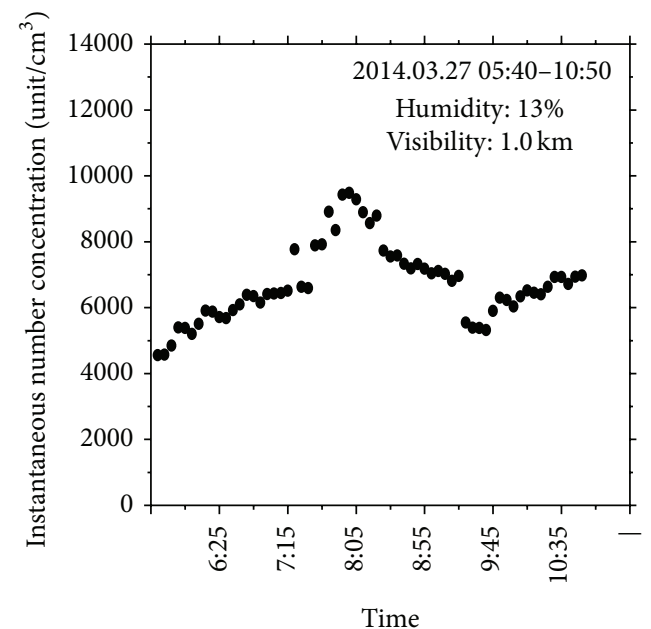

- Blowing dust

(c)

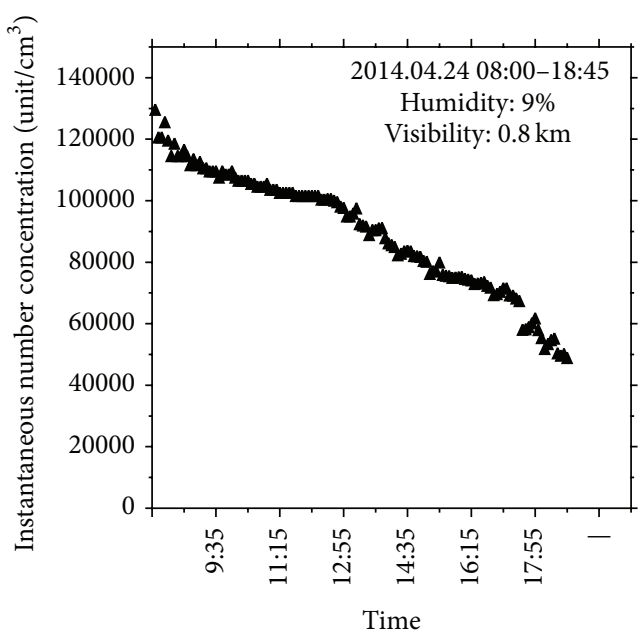

A Sand storm

(e)

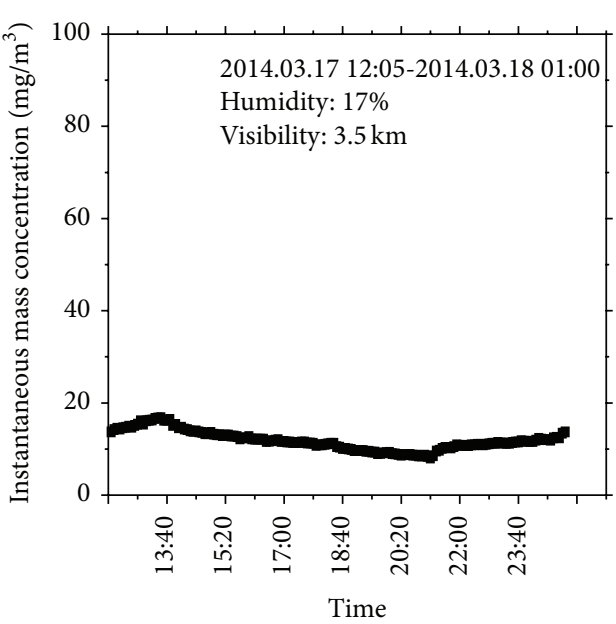

- Floating dust

(b)

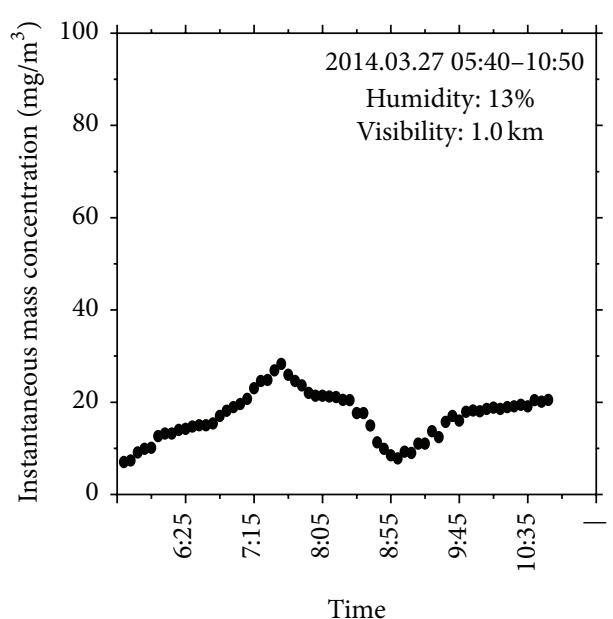

- Blowing dust

(d)

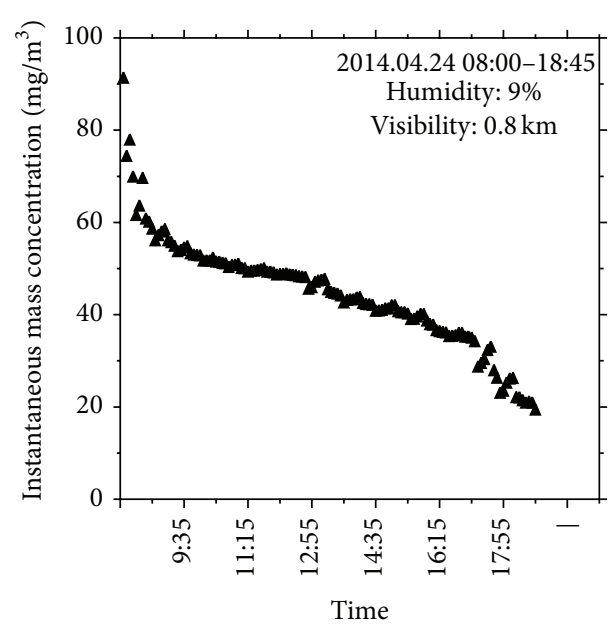

- Sand storm

(f)

Figure 1: Instantaneous number (a, c, e) and mass concentrations (b, d, f) under different meteorological conditions. ((a, b) floating dust; (c, d) blowing sand; (e, f) dust storm). 
dust conditions. From Figures 1(a) and 1(b), the instantaneous dust particle numbers and mass concentrations under floating dust conditions changed only slightly, peaking and then slowly decreasing at a humidity of $17 \%$ and the visibility of $3.5 \mathrm{~km}$. The average wind speed was $6.1 \mathrm{~m} / \mathrm{s}$ and the air masses exchanged slowly. During blowing sand and dust storm conditions, the particle mass and number concentrations changed dramatically. During blowing dust conditions, shown in Figures 1(c) and 1(d), changes in the instantaneous number and mass concentrations were more evident than those during the floating dust process. Concentrations increased at first and then decreased. The average wind speed was about $10.8 \mathrm{~m} / \mathrm{s}$ and the humidity was $13 \%$, and the visibility was $1 \mathrm{~km}$. Under dust storm conditions shown in Figures 1(e) and 1(f), the instantaneous number concentration peaked rapidly and then decreased slowly. Even after the dust storm event, the concentrations still remained high. During the event, the average wind speed reached to $13.1 \mathrm{~m} / \mathrm{s}$, the humidity was $9 \%$, and the visibility was $0.8 \mathrm{~km}$. Wind speeds were highest during dust storm event and lowest during flowing dust conditions; humidity and visibility showed the opposite pattern. From the results, it is clear that the wind speed has a strong influence on dust particle concentrations. It can be seen from Table 1 that the floating dust conditions usually occurred after blowing sand and dust storm events. This is because wind speeds decreased and humidity increased after blowing sand and dust storm events, which decreased dust particle transport and concentrations. Wind speed and humidity play important roles in the transport and suspension of dust particles in the air. Around Yinchuan, dust particles mainly originated from surrounding deserts and were transported in the upper atmosphere.

Because particles with diameters less than $2 \mu \mathrm{m}$ play important roles in atmospheric aerosol extinction and health, $2 \mu \mathrm{m}$ was selected as the demarcation point for defining fine and coarse particles and for calculating the ratio of the number concentration of particles with diameters $\leq 2 \mu \mathrm{m}$ to the total particle concentration. For dust aerosols, existing research has shown that smaller particles strongly scatter shortwave radiation. Larger particles strongly absorb long wave radiation [9].

Figure 2 shows the calculated fine particle ratios at different times during floating dust, blowing sand, and dust storm dust conditions. During floating dust, blowing sand, and dust storm events, the average ratios had ranges of $0.88-$ $0.94,0.84-0.88$, and $0.77-0.83$, respectively. The smallest ratios resulted in the lowest visibility. And during dust storm events more solar radiation scattered than floating dust events because there were a bigger number of fine particles. After floating dust and blowing dust conditions, the fine particle ratios increased, while after dust storm conditions the fine particle ratio decreased. After blowing sand and dust storm conditions, their fine particle ratios were similar because the decreased wind speeds resulted in more coarse particles being deposited to the ground.

3.2. Analysis of Average Dust Particle Size Distributions. Table 2 presents statistical results from the dust particles measurements in Yinchuan. Table 2 shows that the particle number and mass concentrations during the dust conditions studied were 4-9 times greater than during background meteorological conditions, while the mass concentrations during dust storm events could be 44 times greater than during background meteorological conditions.

Figure 3 presents the average particle size distributions during the different meteorological conditions. The average particle size distributions during all of the meteorological conditions were unimodal, but the peaks moved towards larger particle diameters as conditions went from background to dust storm. During a background day, the peak was located at approximately $0.7 \mu \mathrm{m}$ and the number concentration was $88 \mathrm{units} / \mathrm{cm}^{3}$. Almost no particles had diameters greater than $10 \mu \mathrm{m}$. Under floating dust conditions, the peak was located at approximately $1.1 \mu \mathrm{m}$ and the number concentration was 300 units $/ \mathrm{cm}^{3}$. Most particles were less than $2.5 \mu \mathrm{m}$ in diameter. The peak concentrations of floating dust process are about 3.4 times to background day. Under blowing sand conditions, the peak was located at approximately $1.3 \mu \mathrm{m}$ and the number concentration was $390 \mathrm{units} / \mathrm{cm}^{3}$. The diameters of most particles were less than $5 \mu \mathrm{m}$. The peak concentrations of blowing sand process are about 4.4 times bigger than background day. Under dust storm conditions, the peak was located at approximately $1.5 \mu \mathrm{m}$ and the number concentration was 640 units $/ \mathrm{cm}^{3}$. Most particles were less than $10 \mu \mathrm{m}$ in diameter. The peak concentrations of dust storm process are about 7.3 times bigger than background day. It is clear that during dust storm event, particle concentrations are much higher than during other times and the high wind speed associated with dust storm contributes to the larger particle diameters.

The average surface area size distribution during a background day was unimodal, with a peak at $0.7 \mu \mathrm{m}$ and a surface area concentration of $139 \mu \mathrm{m}^{2} / \mathrm{cm}^{3}$. Average surface area size distributions during the other three meteorological conditions were bimodal. The two peaks for floating dust, blowing sand, and dust storm conditions were located at 1.7 and $11.1 \mu \mathrm{m}, 1.8$ and $12.0 \mu \mathrm{m}$, and 2.5 and $12.9 \mu \mathrm{m}$, respectively, and the associated surface area concentrations were 1990 and $133 \mu \mathrm{m}^{2} / \mathrm{cm}^{3}, 2280$ and $150 \mu \mathrm{m}^{2} / \mathrm{cm}^{3}$, and 4840 and $449 \mu \mathrm{m}^{2} / \mathrm{cm}^{3}$, respectively. The increased number of particles during dust storm events clearly has a strong influence on the high average surface areas measured. It is shown in Figure 3 that the average surface area size distribution curve of dust storm has an upward trend and it does not tend to zero. This shows that in the dust storm event although the number of large particles is small, they have great contribution to the surface area concentration. In fact in 1988 Zhao et al. had found that the volume size distribution and mass distribution of Beijing in winter are trimodal. The peaks of volume size distribution are $0.7 \mu \mathrm{m}, 3.0 \mu \mathrm{m}$, and $12 \mu \mathrm{m}$. The peaks of mass distribution are $0.9 \mu \mathrm{m}, 4.0 \mu \mathrm{m}$, and $15 \mu \mathrm{m}$ [20].

The average mass size distribution during the background day was unimodal, with a peak located at $2.8 \mu \mathrm{m}$ and a mass concentration of $0.04 \mathrm{mg} / \mathrm{cm}^{3}$. Each of the other meteorological conditions showed bimodal distributions. During floating dust, blowing sand and dust storm conditions 


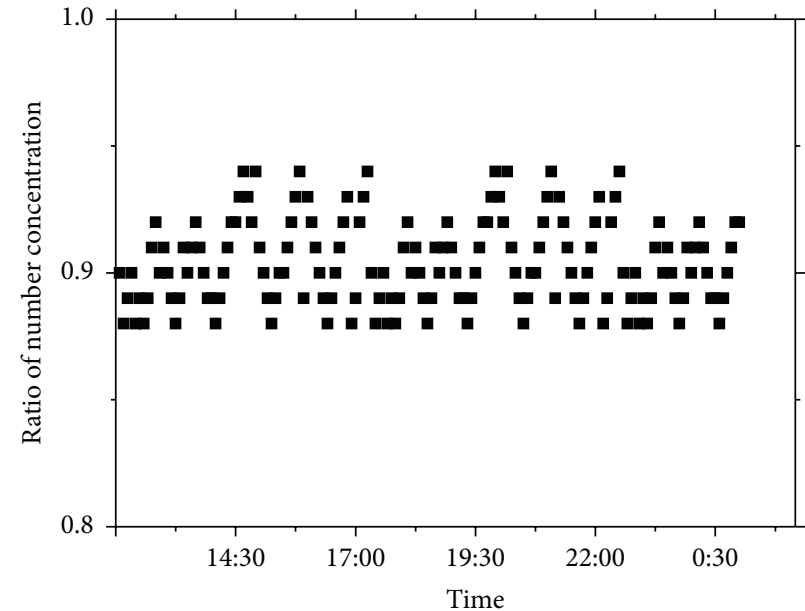

- Floating dust

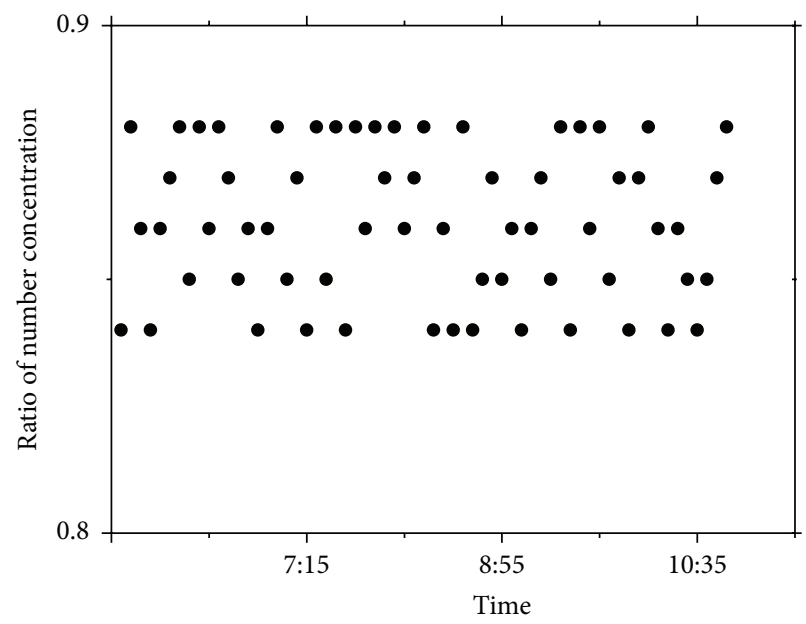

- Blowing dust

(a)

(b)

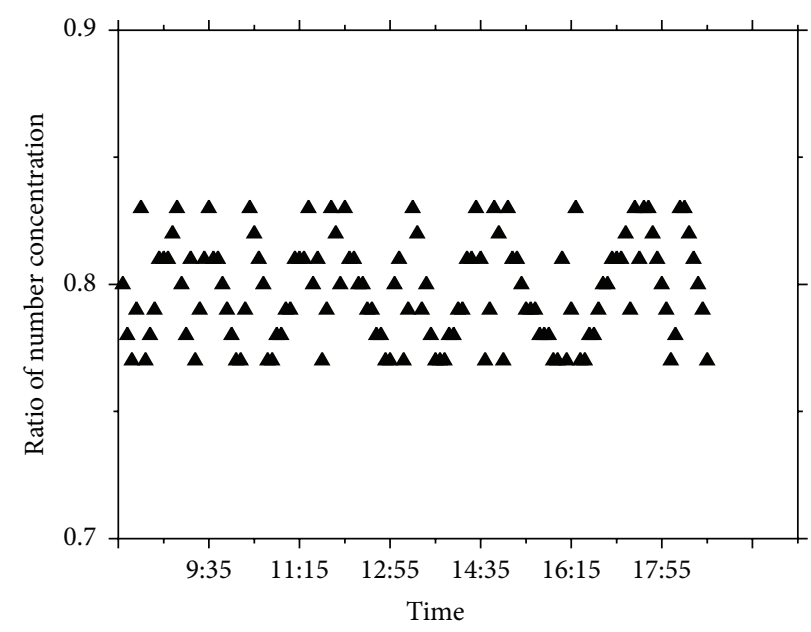

- Sand storm

(c)

FIGURE 2: Ratios of the number concentrations of dust particles with diameters $\leq 2.0 \mu \mathrm{m}$ to the total number concentrations under different meteorological conditions ((a) floating dust; (b) blowing sand; (c) dust storm).

about the peaks were located at 2.5 and $12.0 \mu \mathrm{m}, 2.5$ and $10.4 \mu \mathrm{m}$, and 3.5 and $14.9 \mu \mathrm{m}$, respectively. The associated mass concentrations were 0.77 and $0.33 \mathrm{mg} / \mathrm{cm}^{3}, 0.9 \mathrm{mg} / \mathrm{cm}^{3}$ and $0.4 \mathrm{mg} / \mathrm{cm}^{3}$, and $2.4 \mathrm{mg} / \mathrm{cm}^{3}$ and $2 \mathrm{mg} / \mathrm{cm}^{3}$, respectively. Because dust storm events produced more large particles and blowing sand particles were larger than floating dust particles, these results are not surprising because larger particles have more mass. The high particle concentrations are likely to pose significant health risks for exposed populations.

3.3. Analysis of $P M_{1}, P M_{2.5}$, and $P M_{10}$ during Dust Conditions. $\mathrm{PM}_{1}$ indicates particulate matter with diameters $\leq 1.0 \mu \mathrm{m}$. $\mathrm{PM}_{2.5}$ and even $\mathrm{PM}_{10}$ can also directly enter the lung. $\mathrm{PM}_{2.5}$ and $\mathrm{PM}_{10}$ represent particulate matter with diameters $\leq$ $2.5 \mu \mathrm{m}$ and $10 \mu \mathrm{m}$, respectively. These small particles contain many toxic and hazardous substances and can be transported large distances because they remain in the atmosphere for a number of days. These particles originate from natural anthropogenic sources, with anthropogenic sources tending to be more harmful to human health. Natural sources include soil and sea salt. Anthropogenic particle sources include many industrial exhaust processes, such as coal, metallurgy, and chemicals. Anthropogenic sources also include some secondary aerosols composed of ultrafine particles in the air.

Table 3 lists the dust particles mass concentrations for $\mathrm{PM}_{1}, \mathrm{PM}_{2.5}$, and $\mathrm{PM}_{10}$ and their associated percentage contributions to total particle mass under the different meteorological conditions studied. $\mathrm{PM}_{1}, \mathrm{PM}_{2.5}$, and $\mathrm{PM}_{10}$ concentrations were low during background conditions, but their percentage contributions to the total mass were large. This is because under background conditions the wind speeds were low and the majority of particles were fine, originating from dust, human activities, and industrial emissions, which 
TABLE 2: Statistical results from dust particles measurements in Yinchuan.

\begin{tabular}{|c|c|c|c|c|c|c|}
\hline Observation time & $\begin{array}{l}\text { Number of } \\
\text { samples }\end{array}$ & $\begin{array}{l}\text { Weather } \\
\text { type }\end{array}$ & $\begin{array}{c}\text { Maximum } \\
\text { number } \\
\text { concentration } \\
\left(\text { unit } / \mathrm{cm}^{3}\right)\end{array}$ & $\begin{array}{l}\text { Minimum } \\
\text { number } \\
\text { concentration } \\
\left(\text { unit } / \mathrm{cm}^{3} \text { ) }\right.\end{array}$ & $\begin{array}{l}\text { Average number } \\
\text { concentration } \\
\left(\text { unit } / \mathrm{cm}^{3}\right)\end{array}$ & $\begin{array}{c}\text { Average mass } \\
\text { concentration } \\
\left(\mathrm{mg} / \mathrm{m}^{3}\right)\end{array}$ \\
\hline 2014.03.17 08:00-11:40 & 45 & $\begin{array}{l}\text { Blowing } \\
\text { sand }\end{array}$ & 4510 & 5880 & 5440 & 19.8 \\
\hline $\begin{array}{l}\text { 2014.03.17 12:05-2014.03.18 } \\
\text { 01:00 }\end{array}$ & 156 & $\begin{array}{l}\text { Floating } \\
\text { dust }\end{array}$ & 5270 & 2030 & 3821 & 11.8 \\
\hline 2014.03.27 05:40-10:50 & 63 & $\begin{array}{c}\text { Blowing } \\
\text { sand }\end{array}$ & 9480 & 4560 & 6724 & 16.9 \\
\hline 2014.03.27 11:25-13:45 & 29 & $\begin{array}{c}\text { Floating } \\
\text { dust }\end{array}$ & 2700 & 1540 & 2211 & 5.2 \\
\hline 2014.04 .01 12:15-21:40 & 114 & Background & 1630 & 597 & 942 & 1.1 \\
\hline 2014.04.24 08:00-18:45 & 130 & Dust storm & 11500 & 5770 & 8803 & 44.3 \\
\hline 2014.04.24 19:10-21:30 & 29 & $\begin{array}{l}\text { Floating } \\
\text { dust }\end{array}$ & 5390 & 3480 & 4482 & 14.7 \\
\hline \multirow{4}{*}{ Average value } & & Background & 1630 & 597 & 942 & 1.1 \\
\hline & & $\begin{array}{c}\text { Floating } \\
\text { dust }\end{array}$ & 5390 & 1540 & 3505 & 10.6 \\
\hline & & $\begin{array}{c}\text { Blowing } \\
\text { sand }\end{array}$ & 9480 & 4560 & 6082 & 18.4 \\
\hline & & Dust storm & 11500 & 5770 & 8803 & 44.3 \\
\hline
\end{tabular}

TABLE 3: $\mathrm{PM}_{1}, \mathrm{PM}_{2.5}$, and $\mathrm{PM}_{10}$ dust particles mass concentrations and mass concentration percentages to total mass under different meteorological conditions.

\begin{tabular}{|c|c|c|c|c|c|c|c|c|}
\hline \multirow[t]{2}{*}{ Weather type } & \multirow{2}{*}{$\begin{array}{c}\text { The maximum wind } \\
\text { speed }(\mathrm{m} / \mathrm{s})\end{array}$} & \multirow{2}{*}{$\begin{array}{l}\text { The mass concentration } \\
\qquad\left(\mathrm{mg} / \mathrm{m}^{3}\right)\end{array}$} & \multicolumn{3}{|c|}{$\begin{array}{l}\text { The average mass concentration } \\
\qquad\left(\mathrm{mg} / \mathrm{m}^{3}\right)\end{array}$} & \multicolumn{3}{|c|}{$\begin{array}{l}\text { Ratios of the mass concentration } \\
\text { to total concentration }(\%)\end{array}$} \\
\hline & & & $\mathrm{PM}_{1}$ & $\mathrm{PM}_{2.5}$ & $\mathrm{PM}_{10}$ & $\mathrm{PM}_{1}$ & $\mathrm{PM}_{2.5}$ & $\mathrm{PM}_{10}$ \\
\hline Background & 3.3 & 1.1 & 0.15 & 0.5 & 1.08 & 13.6 & 45.5 & 98.2 \\
\hline Floating dust & 6.1 & 10.6 & 0.42 & 4.6 & 10.1 & 3.9 & 43.4 & 95.3 \\
\hline Blowing sand & 10.8 & 18.4 & 0.59 & 7.83 & 17.2 & 3.2 & 42.6 & 93.5 \\
\hline Dust storm & 13.1 & 44.3 & 0.61 & 13.2 & 40.3 & 1.4 & 29.8 & 90.9 \\
\hline
\end{tabular}

were likely the main source. During the three conditions, $\mathrm{PM}_{1}, \mathrm{PM}_{2.5}$, and $\mathrm{PM}_{10}$ concentrations increased as wind speeds increased, but their percentage contributions to the total mass concentrations decreased. This highlights the increase in particle size as wind speeds increased, showing that wind is a critical factor to the transport of dust to Yinchuan.

\section{Conclusion}

In Yinchuan, dust particles concentrations had different temporal evolution characteristics under different dust conditions. During floating dust conditions, the instantaneous concentrations changed slowly, peaking and then only slightly decreasing. During blowing dust events, the instantaneous concentrations increased and then decreased in stages. Under dust storm conditions, the instantaneous concentrations of dust particles peaked sharply and then decreased, remaining at a high value.

Under the three dust conditions, the number concentration ratios of particles $\leq 2.0 \mu \mathrm{m}$ to the total number were different. At the end of floating dust and blowing sand conditions, the ratios showed an increasing trend. At the end of blowing sand and dust storm conditions, the ratios were almost equivalent.

Average number size distributions under the three dust conditions were unimodal, with peaks at approximately 1.1, 1.3 , and $1.5 \mu \mathrm{m}$, under floating dust, blowing sand, and dust storm conditions, respectively. The average surface area size distributions during the three dust conditions were all bimodal, with peak at 1.7 and $11.1 \mu \mathrm{m}, 1.8$ and $12.0 \mu \mathrm{m}$, and 2.5 and $12.9 \mu \mathrm{m}$, under floating dust, blowing sand, and dust storm conditions, respectively. During dust storm events, the average surface area size distribution showed an upward trend. The average mass size distributions were also all bimodal, with peaks at 2.5 and $12.0 \mu \mathrm{m}, 2.5$ and $10.4 \mu \mathrm{m}$, and 3.5 and $14.9 \mu \mathrm{m}$, under floating dust, blowing sand, and dust storm conditions, respectively.

During the three dust events, the concentrations of $\mathrm{PM}_{1}$, $\mathrm{PM}_{2.5}$, and $\mathrm{PM}_{10}$ increased as conditions moved towards the duet storm, but their percentage contributions to the total mass concentrations decreased. This is because increased 


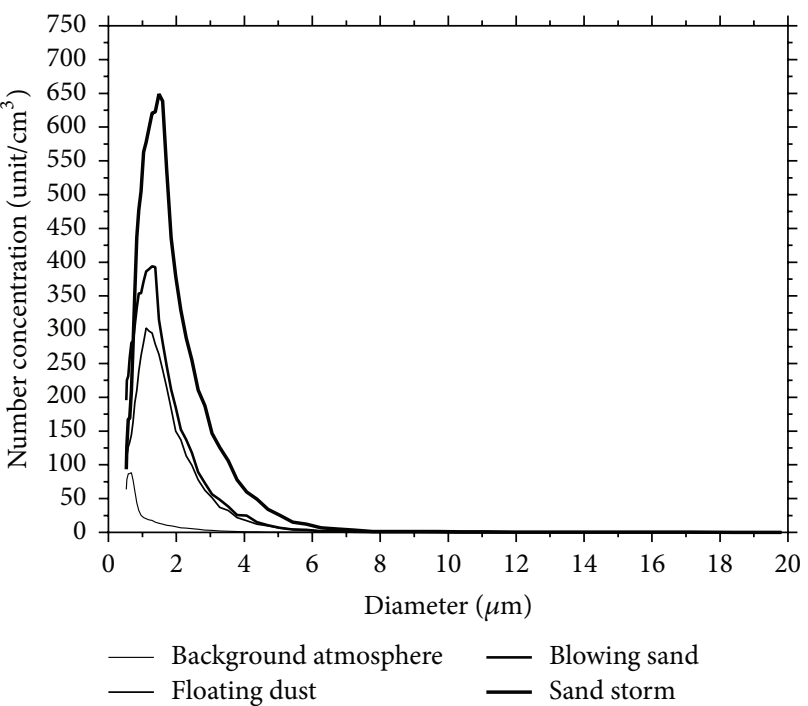

(a)

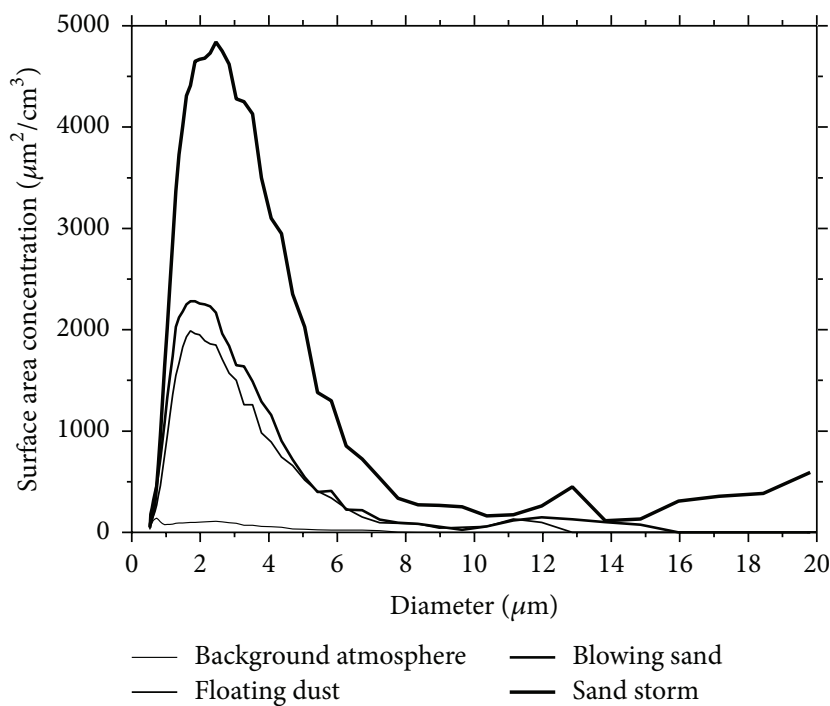

(b)

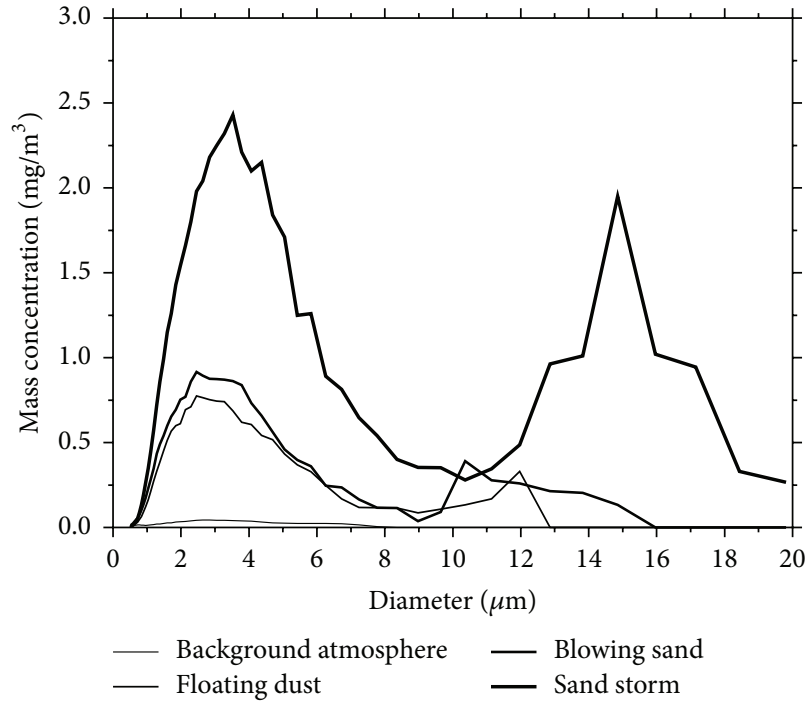

(c)

Figure 3: Dust particles average size distributions during the four different meteorological conditions ((a) average number size distribution; (b) average surface size distribution; (c) average mass size distribution).

wind speeds transported more large particles over long distances.

\section{Conflict of Interests}

The authors declare that there is no conflict of interests regarding the publication of this paper.

\section{Acknowledgments}

This work was supported by the National Natural Science Foundation of China (NSFC) (no. 61168004, no. 61450007, and no. 61565001), the Natural Science Foundation of Ningxia (no. NZ13094), the West Light Talent Plan of the Chinese Academy of Sciences, the Plan for Training Young Talents in the State Ethnic Affairs Commission of the People's Republic of China (no. 2014-3-24), and the key scientific research project of Beifang University of Nationalities (2015).

\section{References}

[1] C. C. Zhang and W. X. Zhou, Atmospheric Aerosol Course, Meteorological Press, Beijing, China, 1995.

[2] Y. J. Zhu, "Observation and analysis of aerosol particles spectrum," Atmospheric Science, vol. 6, no. 2, pp. 217-223, 1982.

[3] P. Paltridge, The Radiative Process of Meteorology and Climatology, Science Press, Beijing, China, 1981.

[4] Z. Y. Hu, R. H. Huang, and G. A. Wei, "The variation of ground meteorological elements and characteristics of the surface energy balance in Dunhuang when sand storm transit 
in the June 4, 2000," Atmospheric Science, vol. 26, no. 1, p. 127, 2002.

[5] W. F. Lei, L. X. Ren, W. X. Lv et al., "Desert aerosol concentration and distribution of spectrum in Heihe Ma J F, Chen F Y. Discussion of causes and Observations of blowing sand and floating dust," Meteorological Science and Technology in Zhejiang, vol. 22, no. 1, pp. 44-46, 2003.

[6] Z. J. Zhou and G. C. Zhang, "Typical dust storms in northern china," Science Bulletin, vol. 48, no. 11, pp. 1224-1228, 2003.

[7] S. G. Wang and D. B. Yang, "Causes and countermeasures of black storm in northwest China," Chinese Desert, vol. 15, no. 1, pp. 19-30, 1995.

[8] T. Wang, G. T. Chen, Z. A. Qian et al., "Situation and countermeasures of sand storm in northern China," Chinese Desert, vol. 21, no. 4, pp. 500-506, 2001.

[9] Y. D. Gu and S. J. Niu, "Dust aerosol instantaneous spectral analysis and fitting in Helan mountain area," Meteorological Journal in Nanjing, vol. 29, no. 4, pp. 500-506, 2006.

[10] D. Z. Yang and C. Wang, "Two characteristics of sand storm in spring in 1990," Journal of Applied Meteorology, vol. 6, no. 1, pp. 19-28, 1990.

[11] G. M. Sverdrup, K. T. Whitby, and W. E. Clark, "Characterization of California aerosols-II. Aerosol size distribution measurements in the Mojave Desert," Atmospheric Environment, vol. 9, no. 5, pp. 483-494, 1975.

[12] J. N. Porter and A. D. Clarke, "Aerosol size distribution models based on in situ measurements," Journal of Geophysical Research, vol. 102, no. 5, pp. 6035-6045, 1997.

[13] J. M. Haywood, P. N. Francis, M. D. Glew, and J. P. Taylor, "Optical properties and direct radiative effect of Saharan dust: a case study of two Saharan dust outbreaks using aircraft data," Journal of Geophysical Research: Atmospheres, vol. 106, no. 16, pp. 18417-18430, 2001.

[14] Y. J. Chun, J. C. Kim, K. O. Choi, K. O. Boo, S. N. Oh, and M. Lee, "Characteristic number size distribution of aerosol during Asian dust period in Korea," Atmospheric Environment, vol. 35, no. 15, pp. 2715-2721, 2001.

[15] J. N. Quan, X. X. Xi, X. Wang et al., "Mass concentration characteristics of san dust aerosol in Lanzhou in 2001," Chinese Desert, vol. 25, no. 1, pp. 93-97, 2005.

[16] S. J. Niu and Z. B. Sun, "Aircraft measurements of sand aerosol over Northwest China desert area in late spring," Plateau Meteorology, vol. 24, no. 4, pp. 35-42, 2005.

[17] T. T. Chen, R. D. Lv, H. B. Chen et al., "Spectral characteristics of dust aerosol in Hunshandake desert," Atmospheric Science, vol. 29, no. 1, pp. 147-153, 2005.

[18] J. F. Ma and F. Y. Chen, "Discussion of causes and observations of blowing sand and floating dust," Meteorological Science and Technology in Zhejiang, vol. 22, no. 1, pp. 44-46, 2003.

[19] C. A. Clayton, R. L. Perritt, E. D. Pellizzari et al., "Particle total exposure assessment methodology (PTEAM) study: distributions of aerosol and elemental concentrations in personal, indoor, and outdoor air samples in a Southern California community," Journal of Exposure Analysis and Environmental Epidemiology, vol. 3, no. 2, pp. 227-250, 1993.

[20] D. Zhao, D. Tang, Z. H. Zhou et al., "Study on aerodynamic size," Chinese Journal of Atmospheric Sciences, vol. 12, no. 2, pp. 140146, 1988. 

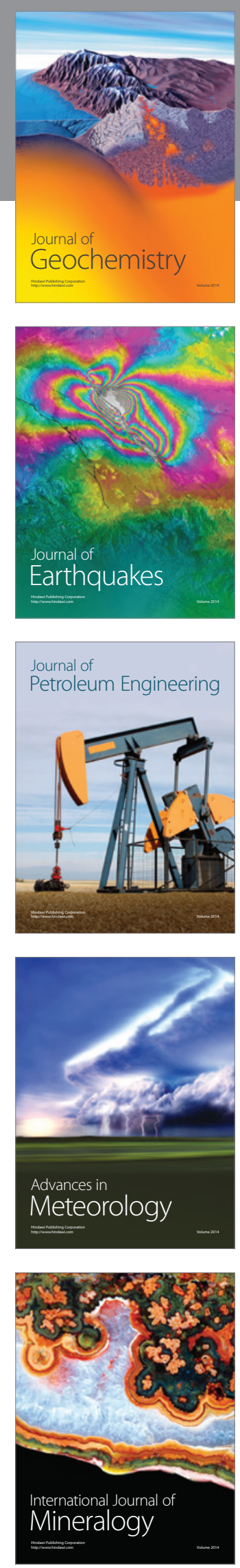
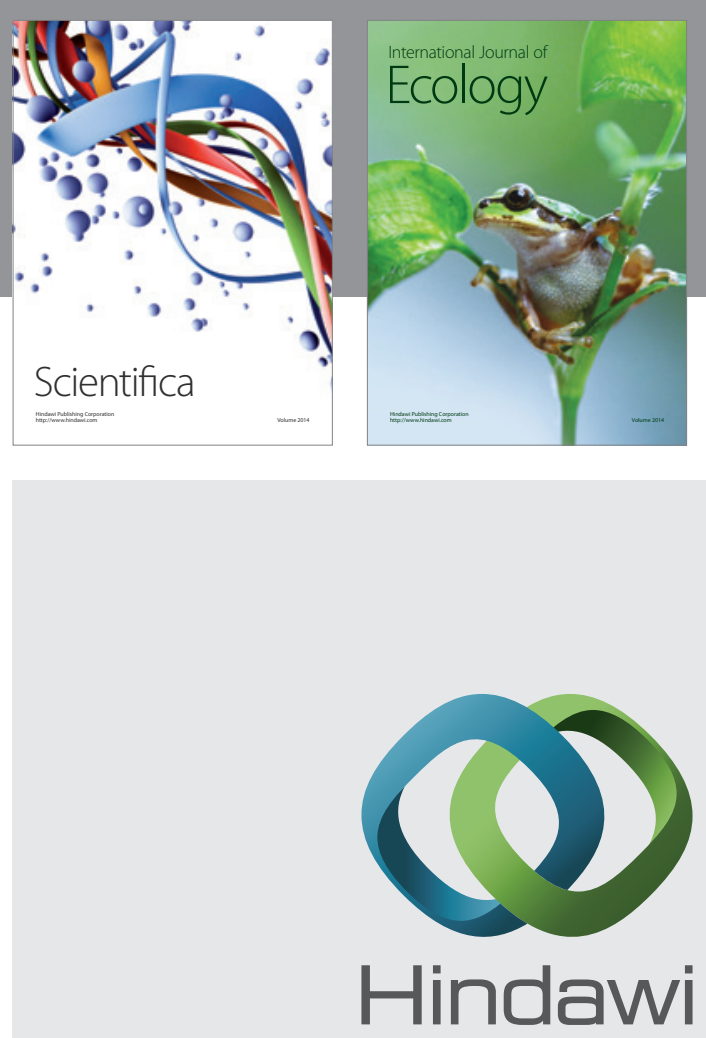

Submit your manuscripts at

http://www.hindawi.com
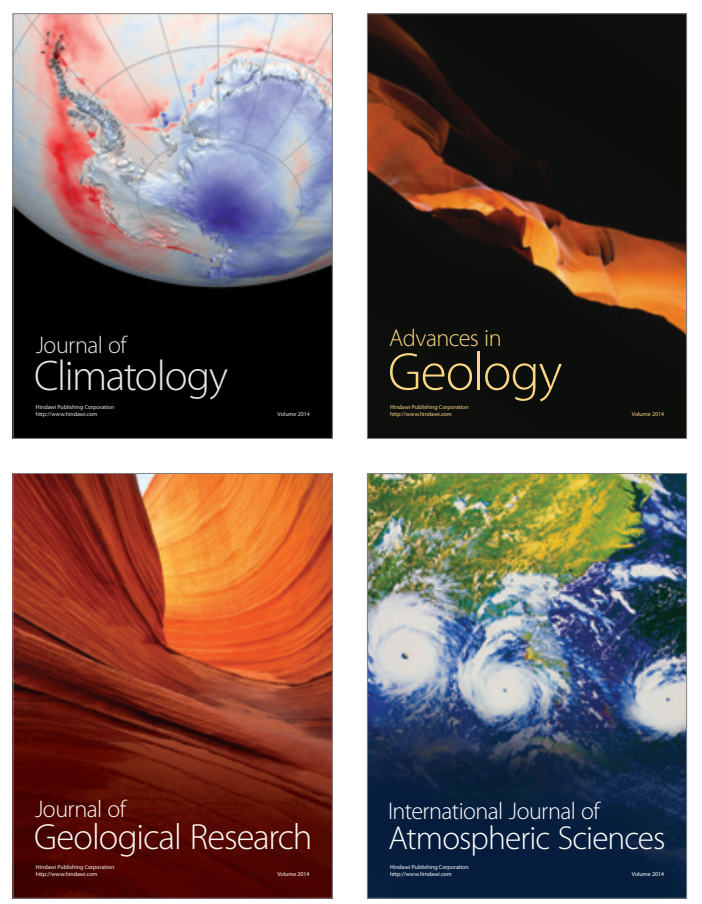

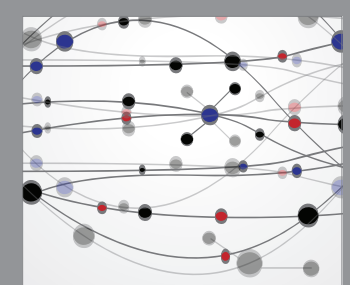

The Scientific

\section{World Journal}
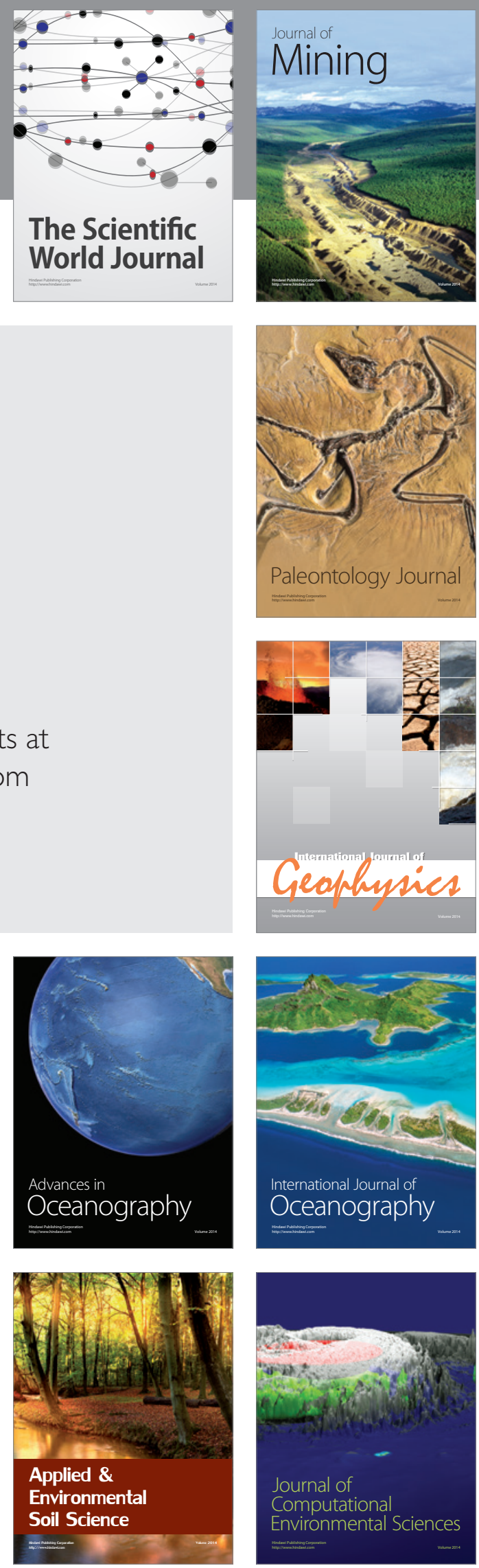